\title{
Enabling Innovation in Complex Welfare Service Systems
}

\author{
Harri Jalonen ${ }^{1}$, Pekka Juntunen ${ }^{2}$ \\ ${ }^{1}$ Turku University of Applied Sciences, Turku, Finland; ${ }^{2}$ University of Lapland, Rovaniemi, Finland. \\ E-mail: harri.jalonen@turkuamk.fi, pekka.juntunen@ulapland.fi
}

Received August 24 $4^{\text {th }}$ 2011; revised September $29^{\text {th }}, 2011$; accepted October $24^{\text {th }}, 2011$.

\begin{abstract}
This paper explores the potential for innovation in welfare services. Using the complexity lens, the paper presents a theoretically founded basis for enabling innovation in complex public-private welfare service systems. The empirical data was collected by conducting semi-structured interviews with leading office holders responsible for social services in the City of Helsinki (Finland) and executive managers of social services producer organizations. As a result, this paper presents and discusses pro-innovation conditions for innovations in welfare services. Pro-innovation conditions consist of four dimensions: 1) creating trust, 2) increasing communication responsiveness, 3) utilising connectivity and interdependencies, and 4) pursuing diversity. This paper claims that the interaction processes have an unknown potential that can be translated into a resource for improving innovation performance in welfare services. The paper also presents research and managerial implications. It is argued that complexity thinking opens up potential for the movement of thought in innovation research. One avenue for future research could be to get more deeply understanding why some organizations are able to be more responsive to evolving innovations than others. In order to answer this question, we suggest elaborating the consequences the conventional management and administrative activities may have on innovation in complex welfare service systems. The paper reflects empirical findings on the literature of innovation and complexity, and thereby might open new insights for practitioners to interpret their own innovation environment. One of the most important issue linked to innovation management is the acceptance of the paradox of "being in charge but not in control". Instead of equaling management with the elimination of uncertainty related to innovation processes, management should be seen consisting of activities that have effects on ongoing interaction processes within the complex welfare service system. These effects can be anticipated, but not fully known. We suggest that managing innovation in complex welfare service systems require the ability to articulate emerging themes, to stand "co-opetition" states of diversity, to acknowledge the boundaries of rational thinking and resist the urge to rapidly draw conclusions, and reflect on one's own behavior and its consequences.
\end{abstract}

Keywords: Innovation Management, Welfare Services, Service Innovation, Welfare System, Complexity Theory, Uncertainty

\section{Introduction}

Increased demand for welfare services, especially due to an ageing population, has raised concerns about the effectiveness of welfare services provision. At the same time, increasingly complicated customer requirements mean that the welfare service system needs to be more responsive. Despite different starting points and motivations, solutions for the above-mentioned issues are explored in the field of innovation research. A rather general assumption is that problems concerning the effectiveness of welfare services and service system responsiveness are only solved if service systems are able to develop innovative working methods and practices. In this sense, innovativeness is seen as a 'silver bullet'-a cure for a disease, which, in the case of welfare issues, manifests itself as either service ineffectiveness or inflexibility within the service system [1-5]. However, despite the broad agreement on the need for service innovation, many organizations still struggle with deficiencies when it comes to innovating services [6].

Today, there is a tendency for a growing number of welfare services to be provided by co-operation between the public and private sectors. The attractiveness of cooperation is the result of a logic that argues that the challenges of effectiveness and responsiveness on the part of welfare services are solved by combining the comple- 
mentary and substitutive capabilities possessed by different organisations. There are many alternative points of view with which to examine these tendencies for co-operation-such as networks, public-private partnerships and governance. In the twenty-first century we can talk about "public management networks": officials exchange information, manage knowledge and address problems of mutual concern. Organizations collaborate and network for public purposes, e.g. matching services, or solving policy problems [7], or creating "shared value" [8]. In network management it is essential to account for differences within a network because the differences provide strategic opportunities and constraints for managers involved in coordinating mixed-sector networks [9].

Public-private partnerships (PPP) have been much discussed throughout Europe. PPP is defined as "cooperation between public and private actors with a durable character in which the actors develop mutual products and/or services and in which risk, costs and benefits are shared” [10]. In an ideal PPP, the traditional distinction between public and private is dissolved, and the public and private partnership is based on the idea of mutual added value [10]. Partnerships are organizational manifestations of institutional design for collaboration [11].

The term "governance" has been used in a variety of ways, but is most often presented as an attempt to improve co-ordination between relatively dependent, autonomous actors. It involves the horizontal steering of relations across networks [12-14]. Operating in the complex environment of action, new forms of governance have to be taken into account by recognizing the need for interaction and co-operation between the public, private and other actors.

It is mixed-sector co-operation that is seen to provide fertile ground for innovations in welfare services. However, while co-operation increases innovation potential in welfare services, it should be noted that co-operation also creates complicated organisational interlacings, which, in turn, may lead to a situation where this innovation potential remains unrealised. In this paper, it is public-private partnerships that are seen as producing complexity in welfare services. In a sense, this paper can be considered a continuation of the (complex) governance paradigm [12, 15-19] Despite subtle differences in nuances between authors, the acknowledgement that governance processes consist of interaction between multiple interdependent actors from the public and private sectors is common for all complexity-oriented governance approaches. The interplay between the actors produces dynamics and complexity-i.e. nonlinear behaviour and unpredictable outcomes-in the "system". In complexity-oriented literature, the system as a "whole" implies an emergent structure that cannot be understood on the basis of what is known about the individual components of these systems. Emergence is based on both the self-organization within the system and the co-evolution between the system and its environment. For the innovation, and for this paper, all of this has two implications: firstly, attention should be paid to the interaction processes between different actors, and secondly, an "open systems" view (instead of "closed system") of the governance processes should be favoured. "Interaction process" refers herein to the activities of the actors-i.e. people; representing themselves and/or organisations [20] whereas "open systems view" includes the idea that resources flow into and out of the organization and that the system is embedded in larger systems [21]. Stressing the significance of the interaction and the open systems view implies that disturbances and triggers originating outside the system are processed endogenously by the actors in the system. Therefore, this paper stresses the quest for innovations through interaction within a complex system and between the system and its environment.

In this paper, innovation is defined as context specific "novelty in action" [22]. This includes the idea that innovation is a specific form of change [23-25]. Innovation is about change because it represents discontinuity or break with the past [25]. This discontinuity challenges the management of public-private relationships in translating new ideas into new forms of action and improved welfare services. Bringing together the promises of innovation and the complexity of public-private partnerships (particularly in the welfare service domain), we pose the following research question: what kinds of enabling practices can be used in supporting innovation in complex welfare service systems?

By "welfare services" we refer to health and social services that are on the responsibility of the public sector. The welfare service providers, i.e. welfare service system, include public organizations, private firms, non-profit associations, and foundations. The resulting welfare service system is complex in the sense that it produces behaviour that cannot be understood as the sum of its parts [26].

Using the complexity lens, this paper endeavours to develop a framework that deepens our understanding of managing innovations in a welfare service system. Instead of unified theory, "complexity lens" refers herein to a wide set of concepts that can be used to explore the dynamics of socio-economic systems [26,27]. Although complexity thinking has gained popularity in the social sciences since the early 1990s, it is still an under-exploited approach, particularly in the domain of innovation in welfare services. Especially sparse are empirical studies and complexity-informed conceptual models [12, $28,29]$. In addition to the lack of previous research, the 
choice of complexity lens can be rationalized for two reasons: firstly, it offers a promising approach for investigating the internal dynamics of innovation in a welfare service system, not forgetting the relationship between the system and its environment, and secondly, it implicitly acknowledges the complexity or the wickedness of issues in public policy [29], particularly in the welfare domain [30]. Adapting Johnston et al. [31], we argue that the complexity lens allows us to raise new questions and explore new approaches to manage innovation in welfare services.

\section{Research Design}

This paper is composed of two parts. The first part concentrates on the concept of innovation and factors that affect the innovation of welfare services in general. The importance of innovation in the welfare domain is discussed, and thereafter the relevance of the complexity theory within the context of innovation in a welfare service system is presented and discussed. This conceptual part is based on reviewing the relevant innovation and complexity literature. As a result of this part, a basic understanding of the phenomenon of innovation in a welfare system is formed.

The conceptual understanding is deepened in the empirical part of the paper by studying the system-level innovation in the Social Services Department of the City of Helsinki, Finland. The 'value network' of a Social Services Department serves as an illustrative empirical case. The methodology of the second part of this paper can be characterized as qualitative in nature, an approach that is common in studies whose purpose is to gain understanding of how practitioners “define the situation” [32]. Qualitative case-study was chosen, because it is flexible and enables in-depth exploration of perceptions from a limited number of enlightened individuals. The empirical part of the paper is based on interviews that were conducted as the first part of a two-year research project called "Managing the value network of welfare services". A term "value network" is used by the city officials. The City of Helsinki is a large municipal organization with around 40,000 employees and an annual expenditure of around 3000 million Euros. Most of the income is derived from tax revenues. Currently, the network of social services is highly fragmented and difficult to perceive. Therefore, the value network has been launched as a strategic concept for describing the complex operating environment. The Social Services Department has five responsibilities: Child Day Care Services, Services for Families with Children, Adult Services, Elderly Services, and Management and Development Centre. The department produces welfare services in about 750 units. Services are also bought from over 500 external producers. The amount of out- sourced services has steadily increased and in 2010 the department was buying services with about 220 million Euros. The value network of the Social Services Department has formed over a long historical continuum and today it forms a multi-layer network of very diverse agreements and relationships. This particular service system provides an interesting field for the development of system-level innovation thinking due to its societal importance and its highly intangible outputs and outcomes. Adapting the open systems view, the value network of the Social Services Department of the City of Helsinki is embedded in a larger system-i.e. the Finnish Welfare State [33].

The empirical data was collected by conducting 17 semi-structured interviews with leading office holders responsible for social services in the City of Helsinki $(n=9)$ and executive managers of social service producer organizations $(n=8)$. All of the interviewees hold a manager or director position in their organization. Based on the experience of the interviewees, it is reasonable to expect that they have "something to say on the topic" [32]. The topics of the interviews were determined by issues identified in the relevant innovation and complexity literature. The interviews included three open-ended questions designed to elicit primary success and failure factors for innovation in the value network of social services in the City of Helsinki. The questions were as follows: 1) Which factors do you think facilitate or hinder the presentation of new ideas in the value network of social services? 2) Which factors do you think facilitate or hinder the adoption and implementation of the new ideas in the value network of social services? 3) How are the citizens/ customers engaged in the innovation processes of the value network of social services?

The interviewees were selected on the basis of their positions and their experience. Each interview lasted approximately 60 minutes to 90 minutes and was recorded on an audio tape. The recording tapes were transcribed. The empirical material collected in these interviews, were analyzed by using Yin's [34] pattern matching logic. In this paper, pattern matching refers to a method where interview material was interpreted by the concepts of complexity theories. In the interpretation stage, two internal workshops were held in which information gained from the interviews was discussed by all five researchers engaged in the research project (Managing the value network of welfare services). This was done in order to avoid the tendency to confirm the individual researcher's personal preconceived notions [35,36]. Information-processing biases were reduced "by looking at the data in many divergent ways" [36]. The results of the interviews are presented and analyzed in the same section together 
with the quotes from the interviews. The role of the quotes is meant to elaborate the ideas being dealt with. For reasons of space, we are obliged to choose a limited number of quotes. However, they are meant to be as indicative as possible. Instead of structuring the empirical findings into a question-and-answer format, the empirical findings and the discussion are combined and presented in the same section. This kind of composition is quite typical in exploratory studies that debate the value of further research into various propositions [34]. The purpose is to present the information gained from the interviews in its "diversity, allowing the story to unfold from the many-sided, complex, and sometimes conflicting, stories" that the actors in the interviews were told [34]. However, in order to avoid a complete mess and to contribute to academics, the empirical findings were structured thematically; on the one hand, the themes are based on the literature and on the other on the analysis of the semistructured interviews. The four themes are trust, responsiveness, connectivity/interdependency and diversity. The themes all resonate with complexity thinking-the theoretical framework of this study. Thus, in addition to improving the readability of the paper, the interpretation of the empirical findings with the concepts of complexity theories strengthens the validity of the research [34].

We believe our study is reliable, valid and objective, both in its empirical material and results. When it comes to the overall reliability and validity of the study, reliability in qualitative research can be measured with the solidity of the empirical findings or the authenticity of the empirical research material. Accordingly, the validity of the research can be measured with the portability and constancy of the empirical results. We think the results of our study (see Section 5) respond well to the research questions and aims of our study. Furthermore, they respond well to our empirical case. Therefore, we argue that our empirical results can be utilized more widely in innovation management research in the welfare/public service context.

\section{Innovation as a Novelty in Action in a State of Uncertainty}

The term innovation refers to a new idea, product, service or technology which is realized [37,38]. This relatively simple definition of innovation comprises two important dimensions. On the one hand, the term innovation is confined to ideas that are both novel and useful. Innovation is more than just a new idea. An idea becomes an innovation when it is being implemented in some community. On the other hand, novelty as criteria for innovation is context dependent. That is, an idea need not have scientific or global novelty to be regarded as an innova- tion. It is the perception of novelty, by those involved, which is central to definition of innovation [38]. It is argued that, in the public sector, innovations are typically evolutionary or incremental in nature [39]. This means that innovation is new to a particular public organization, though it may have previously been applied elsewhere [40].

The social debate concerning innovation has been dominated by the dualistic view of the private and public sector. The general conception is that public sector is bureaucratic, inactive, and constant arena, which provides only a limited space for innovations, whereas in the private sector the firms continuously develop new products and production processes in order to be competitive and survive in the market. The differences in innovation capability between the public and private sector can be explained comparing how these sectors perceive risk-taking and failure. There is a broad understanding in the innovation literature that innovation process requires experimentation and high tolerance for risk-taking and failure [41]. A strong realistic view is that, in business, as in nature "most things fail" [42]. Therefore, private markets thrive because they generate considerable failure [2]. As Bhatta [43] notes, "firms can sustain several failures that shareholders can accept as long as one success yields on an average a positive rate of return". In other words, firms evolve by failure and experimentation. In contrast to firms, in the public sector risks and failures are managed by avoiding them [43]. Public sector organizations rarely have the "luxury of living with several failures regardless of how many policy successes they may have" [43]. Furthermore, it is argued that the public sector suffers from the lack of success mechanisms. Borins [37], for example, has pointed that the public sector has "asymmetric incentives” for innovations. Incentives are asymmetric, because successful innovations are not rewarded, while unsuccessful innovations may have grave consequences. Especially innovations that decrease the need for resources are averted in the public sector because they cause to lose stature and prestige of the public-service institution [23]. However, despite the above mentioned problems, innovations have grown increasingly popular in recent years also in public services $[1,2,5,15,37,44]$. Demand for innovation has been a central argument of New Public Management (NPM) [2]. NPM refers here to a set of administrative doctrines that target improving efficiency in the public sector by increasing the public sector manager's operative autonomy, which, at best, is realized as a higher degree of flexibility [45]. Innovations are needed partly due to increasing pressure to respond to the demands from the customers and partly due to diminishing resources for supplying services. In an evolving economy, there will be an ongoing need for innovations also in the 
public sector [5].

According to Fonseca [46] and Aasen [47], the main concern for innovation researchers has focused on the question of how organizations should innovate, rather than the question of how they actually do so. Therefore, it is not surprising that innovation processes "are seen as consecutive acts of creation and adoption of novelty, intended to lead to value creation both for the creating and the adopting organizations" [47]. The mainstream thinking in innovation research seems to be that it is possible to design a system that has the capacity to innovate [46, 47]. A little pointedly, it can be said that this kind of thinking is based on the assumptions of rational decision making and perfect information. Rational decision making and perfect information refers to a situation where individual can choose among alternatives by relating them to goals. This also involves individuals understanding the consequence of every choice in relation to a particular goal. By revealing the causes and effects of each phenomenon, systems can rationally "align" themselves with the changing environment.

However, in practice, rational decision making and perfect information are unlikely to be correct for realworld situations. In the words of Fonseca [46], the problem is that "all these [rational] activities do not resonate with experience of everyday life". In the real world, noone has full knowledge of every possible alternative and its various outcomes. Instead of rationality, individuals' behaviour can be characterized as bounded rational [48]. It is bounded rational because of limited information and because of limited cognitive capabilities. In the context of innovation, bounded rationality manifests itself as uncertainty about the future. Uncertainty is a result of an innovation because it "presents an individual or an organization with a new alternative or alternatives, as well as a new means of solving problems" [38]. The existing literature identifies several sources of uncertainty in the innovation process. Bessant [49], for example, has categorized innovation uncertainty as falling into technological, market and political/economic/regulatory uncertainty. Souder and Moenaert [50] have offered a little more accurate categorization and have indentified four sources of innovation uncertainty: consumer, technological, competetive and resource uncertainty. Cantarello et al. [51], in turn, have stressed behavioral uncertainty around innovation. Furthermore, Macdonald and Jianling [52] and Halbesleben et al. [53], among others, have identified the timing of innovation as a source of uncertainty.

Based on the above, it is argued that decisions in innovation processes are without exception made on a high level of uncertainty. This is because the most important decisions, with the greatest implications, are made in the early stages of the innovation process, before all the re- levant information is available [54]. Decision uncertainty is partly due to a lack of information [55] and partly due to the existence of multiple interpretations [56]. Whether uncertainty is a result of information scarcity or information ambiguity, it is obvious that uncertainty is, in most cases, an uncomfortable state for individuals [38], and, this being the case, people seek information that helps them to distinguish between the options and make one appear more attractive or more likely than another [57]. In other words, individuals seek information in order to create a feeling of control over events [58]. Information is sought in order to reduce the uncertainty related to innovation.

Nonetheless, despite any possible 'negative feelings' caused by uncertainty, within the context of innovation, uncertainty also has a positive or at least neutral meaning. Johnson [59], for example, has linked uncertainty and entrepreneurship. Johnson [59] portrays the tolerance of uncertainty and ambiguity as a necessary condition for making things happen. Similarly, Gerwin and Tarondeau [60], Souder and Monaert [50] and van Riel et al. [61] have argued that innovation is a process of coping with uncertainty. Hanft and Korper [62], Rogers [38] and Foster [63] have offered a more positive approach to uncertainty. According to them, uncertainty is a necessary condition for innovation because it may actually improve decisions and can help to achieve agreement when "honest differences in fact and values might otherwise lead to intransigence" [62].

Whether innovation is seen as a phenomenon engendering uncertainty (which should be reduced by information seeking) or as a necessary condition for innovation, the mounting literature concedes that innovation take place more often within and in cooperation between individuals in different organizations [38,64-66]. Problems caused by limited information and limited cognitive capabilities are more often reduced by enlarging the number of participants. Collective action and social support are needed for creating meaning with which to interpret the complex world and for reducing the feelings of uncontrollability [58]. For example, the concept of open innovation is increasingly applied to a situation where knowledge and experience is exchanged across organizational boundaries [67]. It seems that we have come to era where innovations are more often developed within a complex set of relations between actors with various different backgrounds. Given the potentiality of collective actions in reducing the inherent uncertainty in innovation, we propose that the mystery of innovation hides in complex intra- and inter-organizational interaction processes. It is these complex interaction processes that are fundamental for creating innovations that are based on the notyet-known. Therefore, we also need to elaborate the es- 
sence of complexity in the welfare services domain.

\section{Complexity Lens in Understanding Innovation in a Welfare Service System}

It is widely argued that the public sector environment is more complex than that of the private sector $[15,68]$. A common perception is that the complex operational environment imposes special requirements, which drive the welfare sector to implement new kinds of patterns. In spoken language, complexity often means a situation or problem that is difficult to understand or is complicated to handle. In this paper, complexity is seen more precisely: it is a basic property of a system. This paper treats complexity as a 'handle concept' that is used to discover new perspectives on managing innovation in the context of welfare services. Mitleton-Kelly [26], for example, considers complexity neither :bad" nor "good"; for her, it is just that it helps us to understand the nature of the world —and the systems—-we live in [26]. However, in this paper we use complexity more in a positive rather than negative manner. Adapting Morcöl [69], we make the case that "complexity is not just a negative designation ("that the world is too complex to comprehend"), but a positive one". The strength of complexity thinking is that it may explain why the whole is more (or less) than the sum of the parts and how all its components come together to produce overarching patterns as the system evolves and adapts [26,70]. We consider the complexity lens a fresh approach to exploring innovation in a complex welfare service domain.

In the social sciences, complexity theory gained popularity during the 1990s, particularly within the work of Kooiman [71], Luhmann [72], Byrne [73] and Cilliers [74]. Operating with concepts such as dynamics, complexity and diversity, Kooiman [71], for example, argues for new forms of governance that recognize the need for interaction and cooperation between public, private and other actors. In the 2000s, governance issues have been addressed from the complexity view, as in the work by Stacey and Griffin [75], Meek et al. [18], Klijn [12], Teisman et al. [76] and Morcöl [28].

Nonetheless, it should be noted that the complexity does not comprise a single, unified theory, but rather a family of theories arising from the fields of biology, physics, chemistry, computer simulation, evolution and mathematics [26,27]. Mitleton-Kelly [26], for example, emphasizes that complexity theories or thinking enriches traditional systems theory by amplifying the additional characteristics of complex systems and by stressing their inter-relationship and interdependence. In the words of Morcöl [69], "complexity theory offers a structural (sys- temic) understanding of complexity”. Complexity manifests itself in the relationships and interdependencies between actors, and the systemic wholes they constitute together [69]. Hence, adapting Eppel [29], we argue that contrary to the conventional notion of thinking, which stresses the achievement of optimal or best solution to problems, the complexity lens indicates that we need to think about the conditions that facilitate the "pro-innovation" emergence in local contexts. Instead of seeing innovation as a "rational" process that consists of "consecutive acts of creation and adoption of novelty, intended to lead to value creation both for the creating and the adopting organizations" [47], this paper proposes that innovation emerges from complex intra- and inter-organizational interaction processes within the welfare service system. In other words, innovations cannot be imposed; rather, they emerge from the auspicious conditions [76,77].

Despite the potential of complexity thinking for interpreting innovation processes in complex welfare systems, it has some limitations too. One of the most significant limitations relates to the roots of complexity thinking. As Mitleton-Kelly [26], Mitchell [27], Pollitt [78] and Eppel [29], among others, have stated, complexity-oriented ideas and concepts have their origins in the natural sciences. Due to the history of complexity thinking, we agree with Morcöl [28,69], who has argued that researchers should be aware of some fundamental differences between natural and social systems-not least the fact that people are capable of taking purposeful actions. Contrary to natural objects, predicting human behaviour is difficult (or impossible) since "people learn and adapt and change" [29]. People can behave unpredictably and intelligently at the same time. They have, for example, multiple identities and can fluidly switch between them without conscious thought [77]. They can also make decisions based on their previous experience, rather than logical, definable rules [77].

Complexity thinking has also received criticism because of its perceived inability to offer an explanatory value. Pollitt [78], for example, has criticised its usefulness for studying public administration, public policy and governance. The focus of Pollitt's critique is that complexity thinking does not comprise an articulated framework-a distinct theory from which empirically verifiable claims can be derived. While understanding the main point of Pollitt's critique, we argue that the real value of complexity thinking is in its ability to challenge some long-held scientific views, like reductionism and linearity [69]. Complexity thinking challenges some basic assumptions of Newtonian science that underlines scientific management [77]. Contrary to Newtonian science, which is grounded on certainty and predictability and encourages simplifica- 
tions in management, complexity thinking argues that change and uncertainty are basic properties of a complex world and therefore simplifications in management will fail. Adapting Morcöl [69], we consider complexity not as a theory in a strict manner but as useful approach, since it "makes us appreciate the complex nature of the realities and uncertainties in knowledge processes this complexity generates". Perhaps, the strongest argument for complexity thinking is its potentiality to address uncertainty inherent in innovation processes-particularly in the context of a complex welfare system.

In welfare service system, complexity can be divided at least into three dimensions. Firstly, complexity refers to the feature of the system. A system can be defined as a complex system if it exhibits an emergence phenomenon occurring due to the connectivity and diversity of its parts. According to Goldstein [79] "emergence” refers to the "coming-into-being of novel, "higher" level structures, patterns, processes, properties, dynamics, and laws, and how this more complex order arises out of the interactions among components that make up the system itself". An emergent whole is more or less than the sum of its parts. Instead of being "a magical sundering of causality", an emergence refer herein to "an outcome of variegated and constructed dynamics generated out of interactions" between the lover level actors that constitute the system [80]. This means that, while the complex system is aggregated from its parts, the interplay of these parts produces emergent patterns which cannot be analytically reducible to the constituent parts [70]. Emergence results from the process where each welfare service provider (i.e. public organizations, private companies, and non-profit organizations) continually decide with which other organizations it will engage, and what information and other resources it will exchange with them [80]. Furthermore, in the context of welfare services, customers/clients have important roles to perform in service operations. They participate and influence both the production and the outputs, for example, by providing information about their health and by exercising rehabilitation actions [81]. Viewed with the complexity lens, relationships between the system and its environment create nested, interacting and interdependent systems $[29,82]$. This means that the value network of the Helsinki Social Services Department is an open system in the sense that it exchanges information, resources and ideas with its environment [29]. That is to say that the value network co-evolves with other systems. What is important is that innovations are emergent and result if at all from dynamic interaction and feedback processes both within the actors in the welfare systems and between the system and its surrounding environment.

Secondly, complexity arises from the nature of the is- sues in the welfare domain. Public policy problems can be characterized as "malignant", "vicious" and "tricky" [2]. Such problems, especially in welfare domain, are "wicked problems" in a sense that they have no definitive formulation; solutions are not true or false; there is no test for a solution; every solution has a consequence; they do not have simple causes; and they have numerous possible explanations which in turn frame different policy responses $[2,83]$. In health care services, for instance, a good example of a wicked problem is the goal to increase the equality in service delivering while simultaneously trying to decrease the costs of the care. In short, a wicked problem is subjective in the sense that everyone can have an equally "right" opinion about it. Therefore, the process of tackling a wicked problem is political it is an argument and a deliberation [30].

This leads to the third feature of the complexity, namely the complexity of objectives and values in public sector. Comparing to private sector, it is said that public sector fulfills various values and pursues multiple goals [84, 85]. Kalu [85], among others, has noted that "whereas efficiency in the private sector is achieved through reductions in the cost of operation and in the generation of profits, efficiency in the public sector is secured through marginal cost reduction through gauging clientele satisfaction as well as procedural adherence to the rule of law, due process and obedience to legislative mandates". Actually, the interpretation of the concept of 'efficiency' is often flawed when applied to the public services. Efficiency refers to how much an organization can produce for a given amount of resources. In welfare domain, the service efficiency is typically measured in terms of units of service (e.g. in bed-days of care) delivered, divided by the units of service (e.g. number of employees) needed. However, this does not offer conception of effectiveness of the services, i.e. what is the amount of 'welfare' these services are provided. The other problem in defining service efficiency as a ratio of input/output process is that it is only meaningful with respect to assets and services that already exist. As Potts [5] notes "it excludes from the outset criteria that relate to the innovation of new services because the efficiency criterion is meaningless in such cases”. Many authors [2,5,43] have concluded that public sector suffers 'innovation deficit' which can be explained by the detrimental side-effects of pursuing efficiency. According to Potts [5] innovation is difficult in the public sector because the goal of efficiency is inconsistent with the goal of innovation. Paradoxically, "good values” such as efficiency, accountability, and transparency may lead emergence of higher lever [a]dynamics, which can ossify the structures of welfare provision. An emergence, in this sense, manifests itself as inability of the welfare service system to change and grow through 
experimental endeavour in order to meet new environmental threats and opportunities [2,5]

It is evident that an evolving economy requires evolving policy. We think that at the heart of this evolving policy is the welfare service system's ability to generate innovation in consequence of new ideas, along with change in the capabilities, organization, connections and behaviour of the actors that compose the welfare service system [5]. Furthermore, in order to tackle "wicked problems", the welfare service systems must develop dynamic, collaborative and resilient abilities [2,70]. They are needed to craft solutions to wicked problems that the actors involved did not know would occur [2]. In a dynamic, collaborative and resilient environment experiments and also failures are tolerated. Adapting Schön's [86] and Parsons [2] ideas of a learning system, we propose that story of successful innovation is actually that "form follows failure". Potts [5] has nicely captured this role of failure in innovation when he argued that "when fear of failure replaces a capacity to experiment and create trial and error learning, the result is unlikely to be an artefact that actually works". The problem is that, as mentioned earlier, an innovation that does not work is not an innovation at all. From the point of view of this paper, the real issue, therefore, is, on the one hand, how to facilitate processes of "seeing things in the new way", and, on the other hand, how to ensure that "things are done differently". In other words, what kinds of enabling practices can be used in supporting innovative actions in complex welfare systems. We argue that what is needed is not "good design" for innovation per se, but creating conditions that allow (positive) emergence to occur. Adapting McLaughlin et al. (2002), we think that the secret of innovation in the public services lies in managerial actions rather than administrative structures. It is people who innovate, not administrative artefacts.

Before considering the pro-innovation conditions in detail, it is necessary give a brief summary of those elements of complexity thinking that are most important in light of this paper (i.e. enabling innovation and coping with uncertainty in innovation). This summary is especially based on work by Luhmann [72], Mitleton-Kelly [26], Aasen [47], Stacey [70] Morcöl [28,69] and Eppel [29].

The feedback processes are reflexive influence patterns that arise from the interaction between the system parts and between the system and its environment. Without interaction and feedback there is no emergence or self-organization. Positive feedback enhances and stimulates a system's capability, whereas the effects of negative feedback are the opposite (detracting/inhibiting). Self-organization refers to a more or less spontaneous process without externally applied coercion or control, whereas emer- gence means new levels of order. Self-organization consists of phases such as production of uncertainty, chaos, reduction of uncertainty and, finally, new organization. Emergence manifests itself as a complex organizational structure growing out of simple rules. Non-linearity implies that the behaviour of the system may not depend on the values of the initial conditions. In complex systems, dynamic interactions are non-linear i.e., minor changes can produce disproportionately major consequences and vice versa. Nonlinear behaviour is unexpected, unplanned, unfamiliar sequences that may or may not be visible or comprehensible. Connectivity and interdependence points out that actions by any individual may affect (constrain or enable) related individuals and systems. This means that the whole is not to be found in its parts. In addition to connectivity and interdependence within the system, systems are also connected to other systems. The result is nested, interacting and interdependent systems. Therefore, it can be said that a system and its environment co-evolves, with each adapting to the other. Coevolution means that the evolution of one system is partially dependent on the evolution of other related systems, and that change in one system also changes the context of the other(s). Diversity is the state or quality of being different. The diversity of the system's parts spreads into the rest of the system as a result of interdependencies. It can also be said that diversity is the prerequisite source for unpredictable self-organizing and the emergence of novelty. Trust, in turn, is needed for connecting diverse actors. Trust can be seen as a decision through which one can reduce the complexity emerging from the self-organizing interaction processes.

The next section will concentrate on the implications of complexity thinking for innovation in a welfare services system. However, because of the limited scope of this paper, the focus will only be on some aspects of the complexity i.e., those aspects which can be supposed to play an important role in coping with the uncertainty of the innovation process.

\section{Results and Discussion: Enabling Innovation in Welfare Services}

\subsection{Creating Trust}

Trust is generally regarded as one of the most important forces that hold modern societies and their subsystems together $[72,88]$. Metaphorically, it is a social adhesive that gets things going effectively. The function of trust is to balance risk and contingency related to social interaction, and to reduce uncertainty and ambiguity related to the environment and the future. It is said that trust compensates for lack of knowledge.

Trust plays a crucial role also in the context of innova- 
tion in the welfare service system. The interviewees confirmed that trust helps to build up space for creativity innovation, and encourages people to "see things differently". A mutual trust between the people was assessed as a prerequisite for introducing new ideas. One indicative comment was that "...new ideas are often generated when someone discovers the problem. If you can trust that you are not in trouble when you report problems, it could encourage more innovation”. It can be said that trust enables playing with ideas [89]. However, focusing only on the trust between people (personal trust) is insufficient. In complex welfare service system, it is important that there is also trust for the system. Luhmann [90] refers this kind of system trust as confidence. Confidence (system trust) is based on the idea that "social reality is not only dependent on persons but also on functional systems" [88]. The importance of systemic trust is also revealed in the following quotation: "...service providers do not always bring out the problems involved with service provision because they fear that it worsens their position in the negotiations with the Social Services Department. ...it is this uncertainty or lack of confidence that pulls the rug from under the development of new ways of action". In order to act within systems people must have general confidence in their functions. Hence, system trust implies, for example, that the new ideas are given every chance to succeed.

Our results support earlier findings of the meaning of trust in innovation $[2,5,43]$. What is important is that personal and system trust not only reduces complexity and makes up for obscurity caused by imperfect knowledge but also increases certainty, because certainty does not call for correct and certain knowledge but rather the fact that the actors can predict each other's behaviour [88]. We propose, therefore, that trust increases the welfare service system's ability to take risks and stand failures. An atmosphere of trust lowers the mental threshold that suppresses thinking that differs from conventional. In brief, trust supports coping with the uncertainty of innovation.

\subsection{Increasing Communication Responsiveness}

Trust is also needed when new ideas are leading into wrong direction and the course must be revised. This necessitates that ideas can be questioned and compared, as well as that actors are, when necessary, ready to relinquish their restrictive frames of reference [91]. Instead of seeking "one truth", the welfare domain is full of wicked problems which need to be addressed from the multiple perspectives. The majority of the interviewees stressed that in order to change existing practices or services, the goals, consequences and constraints of these changes need to be discussed openly in a collaborative environment. The following quotation about the significance of collaboration is quite representative: “...if you want real partnership, I mean not just rhetoric on partnership, the service delivery should be considered in open and dialogic conversations between service providers and the Social Services Department... dictates do not lead to best outcomes". According to interviews, the most important feature of "open discussion" is responsiveness. By responsiveness the interviewees refer to reciprocal communication and feedback processes where actors of the system co-create relationships that "evoke potential in a trusting environment” [92]. Responsive communication processes create trust, which in turn, can increase the welfare service system's capacity to renew itself and generate new services.

In true life, "openness” of the responsive discussion is always a relative concept. This is because responsive processes are simultaneously both cooperative-competitive in nature [70]. While some subjects can be discussed relatively openly in the welfare service system, there remain always issues which are limited to certain actors. This becomes clear in arguments that stress that cooperation between the service providers is difficult because they are each other's competitors: "The cruel fact is that we [private sector service providers] compete to get the contract with the Social Services Department”. This coincides, for example, with the results by Aasen [47], who has stated that participants in innovation processes quite commonly express that they experience a mutual lack of interest.

Whether cooperative or competitive, however, the most important aspect of these responsive processes is that they have potential to produce positive emergence, which, as earlier mentioned, can lead to innovation. As Stacey [70] writes "novel organizational developments, good or bad, are caused by the cooperative-competitive interaction" which enables and constraints "the creative-destructive processes of organizational development”. The potentiality for "co-opetition” (i.e. collaborative arrangements between two or more competitors while simultaneously competing with each other, cf. [93]), was also identified by the interviewees. A typical comment related to the co-opetition issue was: "it is not reasonable to regard other service providers just as rivals...sometimes the most valuable innovation impulses come from them ...therefore, it is important to seek informal settings where you can meet and exchange thoughts with colleagues from outside your own organization."

Adapting Stacey [70] we argue that innovations are rooted in the interplay of cooperative-competition intentions of actors. Furthermore, we propose that instead on imposing innovation from the "centre of the welfare service system”, innovation should let emerge from the 
"periphery of the welfare service system” [2]. Therefore, the task of innovation management in the welfare service system is not to control actors, but facilitate responsive self-organizing processes, which in the words of Schön [86] include "detecting significant shifts at the periphery, paying explicit attention to the emergence of ideas in good currency, and deriving themes of policy by induction”. Furthermore, we argue for the importance of positive feedback that amplifies changes by reinforcing the direction of the change [29].

\subsection{Utilising Connectivity and Interdependencies}

Responsive communication processes multiply the connectivity and interdependency of elements within the welfare service system and between the system and its environment. At best, the welfare service system co-evolves with other systems. However, according to interviews, this can imply a conflict of interests between two or more entities. At worst, due the dynamics of the connectivity and interdependencies, a micro-scale conflict interest may escalate into a macro-scale phenomenon that threatens the capacity of the welfare service system. The system may become blocked [72]. The following quotation reflects the thoughts of many interviewees: "We don't operate very well on the system level. There are a lot of administrative hurdles between the social services and the health care services... especially in elderly care... These hurdles hinder the development of customer-oriented services... ...sometimes we forget that the customers' problems don't follow the logic of administration." Moreover, the interviewees reported that the responsive processes may have negative side effects. That is to say, the responsive communication entails a risk that increases uncertainty. Because individuals often evaluate new information on the basis of their existing knowledge and mental models, this may lead to a culture where new information is considered more of a threat than a possibility and where ideas that contrast with the existing power structure are rejected [94]. Adapting Gales and Mansour-Cole [95], the situation can be described as a paradox: in seeking to reduce uncertainty, the actors engage in relationships with other, which, in turn, increases the social and political uncertainty of innovation.

The majority of the interviewed representatives of the private service providers agreed with the respondent who claimed that "...it is not easy to talk about new ideas...it seems that they [the Social Service Department] just politely listen to what we tell them...too often ideas remain ideas...ideas don't proceed to the implementation stage...there is some kind of cultural stickiness." It is important to notice that, in light of the interviews, it is not only the Social Services Department that has been ac- cused of being "immune" to new ideas. The following quote typifies the view of several office holders: "Sometimes we ask service providers to introduce new ideas on how to meet the changing needs of citizens. I think it is reasonable to expect that service providers with the best experience in the field could think about services from the new perspectives and develop new kinds of services...However, we have found that there are service providers that are not very agile...it seems like they miss the old good days and don't want to see the reality of what happened." The problems related to the use of information in the innovation process can be understood by the concept of information stickiness [96]. Information stickiness is a result of costs related to the acquisition, transfer and use of information compared to the value or benefit of the information sought [94]. Due the stickiness, information seekers (office holders/representatives of service providers) and information providers (office holders/representatives of service providers) do not encounter each other in a way that they are able come to new insights that were not available based on information from one source. This kind of thinking can be traced back to the philosopher Francis Bacon (1853), who expressed that "the human understanding, from its peculiar nature, easily supposes a greater degree of order and equality in things than it really finds. When any proposition has been laid down, the human understanding forces everything else to add fresh support and confirmation" [35]. In other words, people's information behaviour is biased towards confirmation and verification. Pointedly, we see what we want to see.

In complexity thinking, however, connectivity and interdependency have special role. Luhmann [72], for example, has pointed out that connectivity and interdependency are essential for the system's evolution. MitletonKelly [26] has emphasized similarly, and added that "it is the degree of connectivity which determines the network of relationships and the transfer of information and knowledge". Connectivity and interdependence can be seen as a counterforce for the confirmation-biased information behaviour. In the context of innovation management, the potentiality of connectivity and interdependencies can be explained by the concepts of "strong" and "weak" ties [97]. Strong ties manifest themselves as relationships between individuals or groups that regard each other as similar, which are characterised by a commitment in time, often emotional attachment and intimacy. Weak ties, on the other hand, refer to relationships that connect individuals and groups that usually operate in various social environments. Given that innovation is typically an information-intensive activity [98], we argue that both types of ties are needed in transmission of knowledge in innovation process. The main benefit of different ties is that 
they provide access to knowledge spillovers [98]. Weak ties enable a varied knowledge base, whereas strong ties promote distribution of knowledge particularly in situations where the knowledge is complicated and contextbound [99]. In other words, weak ties improve the welfare service systems' ability to see things "in a new light", whereas strong ties support to convert seeing into "doing differently". Moreover, weak and strong ties increase information redundancy of the welfare service system. Information redundancy is important for innovation, because it means "the use of more elements than necessary to maintain the performance of the system in the event of failure of one or more of the elements" [100]. In other words, information redundancy decreases the fear of failure, which, as mentioned before, is the one of the main obstacle for innovation.

\subsection{Pursuing Diversity}

As mentioned earlier, innovation implies uncertainty, equivocality, and risk of failure. Uncertainty arises from a lack of information across time and from information asymmetry across space [55], whereas equivocality refers to existence of multiple and conflicting interpretations [56]. Due to information uncertainty and equivocality, people prefer "risk aversion", which mean that they take risks on the basis of known rather than unknown probabilities [43]. This kind of bias for "playing safe" [43] may be disastrous in the decision domains around innovation.

Risk-avoiding, fear of failure, and information problems were reported to be barriers for innovation also by the interviewees of this paper as mentioned before in the context of trust. Risk-avoiding, fear of failure and information problems constituted mental constraints that encouraged people towards behaviour of doing nothing. This finding is consistent with the results of previous research, which conclude that the fact that the usefulness of innovation cannot be known a priori may induce public organizations toward playing safe and away from uncertainty and experimentation [2,5,43].

One conceivable approach to the syndromes of "doing nothing" and "playing safe" is to increase the diversity of actors involved in innovation seeking. This argument can be based on the principle of "requisite variety" [101]. A requisite variety refers to a state where systems' internal variety is sufficient to match the environmental variety. The greater the diversity of the welfare service system, the more fit it is [101]. Diversity is a resource that enables to handle uncertainty and ambiquity. Increasing diversity can not only bring new perspectives but also relieve pressures towards conformity, and encourage participation from different actors [29], which, in turn, through feedback loops and interdependencies, improve the system's ability to innovate in the longer term-i.e., seeing things in a new light. The vast majority of the interviewees deemed diversity an essential aspect of the value network of the Social Services Department of the City of Helsinki. A typical statement was as follows: "Diversity is important because the needs of the clients are varied...it is not possible to develop new services without understanding the various needs, and getting understanding requires knowledge that is dispersed between different actors."

Two mechanisms for increasing the diversity of the welfares service system were identified in the interviews. Firstly, most of the interviewees saw that the various needs of the customers can be met by giving them more freedom of choice and responsibility in purchasing welfare services. Many interviewees agreed with the respondent who claimed that "...service vouchers can put pressure on the service providers to innovate new kinds of services. They increase the system's diversity and encourage service providers to develop services that meet the citizens' various needs... Often it is more efficient when the customer is a citizen than when the customer is the Social Services Department". This kind of reasoning is compatible with the current thinking of policymakers. Burwick \& Kirby [102], for example, have noted that service vouchers may increase competition between service providers, which, in turn, may promote diversification of services and improvements in service quality as providers seek to be responsive to the citizens' needs and distinguish themselves in order to attract voucher holders.

Secondly, the interviewees were concerned about the system's ability to absorb ideas developed on the periphery or outside the welfare service system. A typical comment was as follows: "There is no forum where you could express your ideas...many service providers develop small-scale innovations that may also have value for others, but these innovations too often remain hidden and unacknowledged". Based on the interviews, it seems that organizations in the welfare service system face the obstacle of the "not-invented-here" (NIH) syndrome that causes resistance to innovative ideas developed elsewhere [103]. In order to avoid the NIH syndrome, the interviewees recognized the need to be more open to new ideas. This became clear in comments like this one: "the Social Services Department does not actively collect ideas...I think the innovation potential remains unrealized because the Department does not systemically collect and analyze the best practices from the field...this system needs "instrument" that will ensure the dissemination of new ideas." One practical mechanism for avoiding the NIH syndrome is "boundary spanning". This means a loose combination of different functions, duties, processes and roles that are used by the actors who try to 
guide their interaction in a direction that produces results [21,104]. Boundary spanners act as kinds of information filters, thus regulating the flows of information that both come into the system from the environment and go out of the system. In addition to their regulating duties, the boundary spanners function as knowledge interpreters by changing information into forms others can understand [104]. The boundary spanners and the interface elements can be perceived as procedures that have a practical influence that promotes the innovativeness of the welfare service system. They ensure that the welfare service system not only has clearly expressed rules and guidelines but also openness to new ideas and influences, and a willingness to change old patterns.

\section{Innovation Enabling Factors from the Governance Paradigm}

The interaction processes are based on many social and functional factors [105]. The operating culture gives a structure and framework to the interaction process, while the social factors have a significant impact on the participation and commitment of the actors. It can be said that the interaction processes can be promoted or delayed by many social/functional factors.

One can claim that the innovation enabling factors (trust, responsive communication processes, connectivity, interdependencies and diversity) identified in this paper do not offer anything that had not been known before. It is true that there already is a wide consensus on these (and many related) factors. Enabling factors can be linked to many topical discussions concerning public sector management. One of these is the viewpoint of governance. Referring to our research topic of innovation, "governance" can identify these processes, and interdependency and collectivity between actors around innovation actions [106,107]. The governance perspective starts from the diversity, dynamics and complexity of the societies to be governed [108]. Continuing interaction among the actors is essential in complex operative environments [109]. Public administration must be able to manage different networks, and this kind of new structure also involves critical observation concerning traditional ways of action. Referring to our empirical material, the viewpoint of innovation processes is the central one nstead of noticing only the results, it is important to examine the ways of the processes. So, which factors are promoting differrent solutions in innovation actions, and why? As previously mentioned, interaction processes are based on many social and functional factors. Furthermore, when dealing with social services, many political and ideological dissonances exist. From the perspective of governance, practices between administration and politics can be examined, as well as different power dependen- cies between the institutions participating in collective actions.

With this empirical context we argue that managing a value network should be based on governance thinking more than before. Managing with a strong hierarchy and bureaucracy is not the right way to manage decentralized service production networks, or innovation actions within them.

In the context of the examined value network, a few remarks can be adduced from the viewpoint of governance: 1) managing a value network and innovations needs more governance thinking than hierarchical mechanisms towards the managing of a decentralized service production; 2) more instruments for network governance are needed-e.g. managing complex relations between different actors, utilizing the different interaction and dependencies of relations between actors, coordinating different interests, creating cooperative forums, and creating more concrete structures and steering mechanisms for that cooperation; 3) coordination of common strategic actions within the network; 4) enabling common trust, understanding and a "culture of know-how" in service production; 5) considering the nature of the value network-currently, is that ideal (like "ecosystem") one that includes actors with common aims and purposes or is it only an administrative network? Furthermore, we think that this kind of governance thinking will give new instruments and viewpoints for innovation management as well. As we have mentioned earlier, enabling innovations in a complex system is based on utilizing the interactions, interdependencies and diversity of different actors as well as possible.

\section{Conclusions}

This paper has explored the potential for innovation in a complex welfare service system. Using the complexity lens, the first part of the paper discussed the nature of innovation and the special characteristics of innovation in a welfare services context. Innovation was defined as emerging novelty in action in a state of uncertainty. Despite the fact that there is a clear need for innovation in welfare services, the paper argues that, due to the low tolerance of risk-taking and failure, the public sector faces an innovation deficit. Attempts have been made to meet this deficit through co-operation between public and private organizations. However, while such co-operation has increased the potential for innovation, it should be noted that it has also created complex welfare service systems that are difficult to manage. Emergence due to the connectivity and diversity of the system's parts, the wicked nature of the issues in the welfare domain and the complexity of the objectives and values in the public sector were seen as factors that complicate the manage- 
ment of innovation in a welfare service system. The first part of the paper implies that coping with the uncertainty of innovation necessitates that the focus should be on the complex relationships between the actors within the welfare service system and between the system and its environment.

The second part of the paper consists of empirical findings that show that the interaction processes have potential that can be translated into a resource for improving innovation performance in welfare services. An illustrative empirical case was the value network of the Social Services Department of the City of Helsinki, which was defined as complex for three reasons: it is an emergent whole that has arisen out of the interactions and interdependencies between its elements; innovation in the welfare domain is coping with 'wicked' issues in the sense that the best solutions to problems are difficult (or impossible) to achieve; and there is a complexity of objectives and values in the welfare domain, particularly differences in the objectives and values between the public and the private organizations.

Despite the usefulness of the governance paradigm, we think that what is missed or underestimated in traditional governance research related to innovation is the emerging nature of innovation [47]. It is important to note that we do not claim that an emergence is the result of process of pure self-organization. Instead of claiming that innovations "simply happen" or "bubble up", we believe that new order, i.e. innovation, is more appropriately constructed rather than self-organized as such $[80,110]$. Adapting Hazy et al. [80] we think that innovation requires constant support. The "success" of innovation in welfare services depends much on the attention that actors bring to the innovation process. This paper argues that paying attention to trust, responsive communication processes, connectivity, interdependencies, and diversity, it is possible to create favourable conditions for innovations in complex welfare systems.

The main contribution of this paper is that complexity thinking although it does not comprise a single unified theory is a valuable approach since it offers concepts with which to understand the complex processes of innovation in a state of uncertainty. It helps to understand the coexistence of disorder and order the basic dynamics of innovation and the constant transformations from one to the other [69]. In particular, it is useful in the context of the welfare services domain, where the issues are complex by nature because they are social construction processes, because multiple variables affect them and because they are interdependent, subjective and dynamic [69]. Furthermore, seen through the complexity lens, innovation need not only be conceptualized as coping with uncertainty but also as utilizing it. That is to say that the failures always inherent in innovation are not seen as a bad thing, but as a necessary part of the process that produces emergence. As discussed in section five, many enabling factors-e.g. connectivity and interdependencies, and diversity have their "hidden sides", i.e. they may create disorder in the welfare system. In a sense, the complexity lens makes these "hidden sides" visible and integral elements of innovation. Diversity of actors, for example, potentially increases the diversity of ideas, which, in turn, may yield to redundant diversity a state that Fonseca [46] calls "misunderstanding”. Although misunderstanding increases uncertainty, it can be seen as a positive situation. From the complexity point of view, misunderstanding is an example of disorder a necessary condition for the process of self-organization. However, as Morcöl [69], among others, has pointed out, not all service systems are equally self-organizational. Whether uncertainty and disorder in innovation processes act as an engine or as a brake depends on the system's self-organizational capacities. This has been the focus in this paper. We argue that the identified enabling factors are important in improving welfare systems' abilities to innovate.

Paradoxically, the strength and the weakness of complexity thinking are two sides of the same coin. While complexity thinking challenges the human tendency to simplify [69] and change the questions to be asked and answers to be discovered [31], it is, in the words of Pollitts [78], simultaneously "a theory about almost everything, rather than a theory about some specific sector, process or problem". Depending on the point of view, complexity thinking can be seen as fruitful or frivolous.

Despite the limitations of complexity thinking, this paper has identified some research implications. In this way, this paper can be understood as a "springboard" for further theoretical and empirical research. It should be pointed out that complexity thinking implies important epistemological implications. While agreeing with Pollitts [78] critique that complexity thinking does not constitute a universal law from which specific hypotheses of causal relations can be extracted and tested, we argue that complexity thinking can be used to study the dynamic interrelatedness of the parts of complex systems, e.g. public-private welfare systems. On the one hand this means that instead of building a deductive-nomological model, complexity-oriented research is motivated by understanding properties of particular systems. On the other hand, it means that generalizations inspired by complexity thinking are context-dependent. This argument is based on thoughts of Flyvbjerg [111], who has pointed that because the objects of the social sciences are "selfreflecting humans", who are not only interpreted by researchers but also actors who are interpreted as "back" 
researchers, the result is that the social scientific knowledge is contextual. However, despite the epistemological constraints, there are plenty of research possibilities in which the complexity lens would be a valuable approach. One avenue for future research could be to get a deeper understanding of why some organizations are able to be more responsive to evolving innovations than others. In order to answer this question, we suggest elaborating the consequences the conventional management and administrative activities may have on innovation in complex welfare service systems. Research questions could include: how goal setting, planning, monitoring and controlling affect processes intended to lead to innovation, and, at the same time, how such activities function as constraints and enablers for evolving innovations. From the complexity perspective, conventional management and administrative activities such as goal setting, planning, monitoring and controlling are paradoxical. They are paradoxical because they are used to bring 'order' to the innovation process, but, in doing so, they bring down the possibility of self-organization and emergence, which, in turn, are seen as key characteristics of innovation. It would be also useful to study the role of power in innovation in the complex welfare domain. In that case, one interesting research problem could be how power simultaneously works as an enabling and a confining structure for innovation.

This paper has managerial implications too. Based on the literature and the interviews carried out, we claim that there are signals suggesting that complexity thinking may give new insight on innovation management in complex public-private networks. One of the most important issues linked to innovation management is acceptance of the paradox of "being in charge but not in control" [112]. Instead of equating management with the elimination of uncertainty related to the innovation processes, management should be seen as consisting of activities that have effects on ongoing interaction processes within a complex welfare service system. These effects can be anticipated, but not fully known. One practical context in which the findings of this paper can probably be used is when the objective is to improve the innovativeness in contracting practices. This suggestion can be rationalized by the findings of Brown et al. [113], who have shown that discussion of the contracting out practices illustrates the tendency to simplify complex public-private relationships. According to Brown et al. [113], contracting can be divided into two categories: simple and complex contracting. While there are many situations where the process of contracting rules can and should be kept as simple as possible (as in case of copying machines), there are also more complex situations where simple rules cannot apply. This is the case in the welfare service domain, notably in social and health services. In striving for innovative contracting, new management approaches are needed. Adapting Fonseca [46], Stacey [114] and Aasen [47], we suggest that managing innovation in complex welfare service systems requires the ability to articulate emerging themes, to withstand coopetition states of diversity, to acknowledge the boundaries of rational thinking and resist the urge to rapidly draw conclusions, and reflect on one's own behaviour and its consequences.

Finally, it is important to note that the framework presented in this paper is indicative in nature. Obviously, further research should be carried out to validate the framework.

\section{Acknowledgements}

This article has been written as a part of a two-year research project studying the management of the value network of social services in the City of Helsinki, Finland. The project is funded primarily by The Finnish Work Environment Fund. Authors appreciate comments and suggestions for improvements by Dr. Ilpo Laitinen and Dr. Kim Aarva from the City of Helsinki and Prof. Antti Lönnqvist and Dr. Harri Laihonen from Tampere University of Technology on drafts of this article.

\section{REFERENCES}

[1] D. Albury, "Fostering Innovation in Public Services," Public Money and Management, Vol. 25, No. 1, 2005, pp. 51-56.

[2] W. Parsons, "Innovation in the Public Sector: Spare Tyres and Fourth Plinths," The Innovation Journal: The Public Sector Innovation Journal, Vol. 11, No. 2, 2006.

[3] F. Damanpour and M. Schneider, "Characteristics of Innovation and Innovation Adoption in Public Organizations: Assessing the Role of Managers," Journal of Public Administration Research and Theory, Vol. 19, 2009, pp. 495-522. doi:10.1093/jopart/mun021

[4] D. Naranjo-Gil, "The Influence of Environmental and Organizational Factors on Innovation Adoptions: Consequences for Performance in Public Sector Organizations," Technovation, Vol. 29, 2009, pp. 810-818. doi:10.1016/j.technovation.2009.07.003

[5] J. Potts, "The Innovation Deficit in Public Services: The Curious Problem of Too Much Efficiency and not Enough Waste and Failure," Innovation: Management, Policy \& Practice, Vol. 11, No. 1, 2009, pp. 34-43.

[6] N. Dörner, O. Gassmann and H. Gebauer, "Service Innovation: Why is it so Difficult to Accomplish?” Journal of Business Strategy, Vol. 32, No. 3, 2011, pp. 37-46. doi:10.1108/02756661111121983

[7] R. Agranoff, "Managing within Networks: Adding Value to Public Organizations,” Georgetown University Press, Washington D.C., 2007. 
[8] M. Potter and M. R. Kramer, "The Big Idea: Creating Shared Value,” Harvard Business Review, 2011.

[9] J. Herranz, "The Multisectoral Trilemma of Network Management," Journal of Public Administration Research \& Theory, Vol. 18, No. 1, 2008, pp. 1-31. doi:10.1093/jopart/mum004

[10] E.-H. Klijn and G. R. Teisman, "Institutional and Strategic Barriers to Public-Private Partnership: An Analysis of Dutch Cases,” Public Money and Management, Vol. 23, No. 3, 2003, pp. 137-146. doi:10.1111/1467-9302.00361

[11] C. Skelcher, N. Mathur and M. Smith, "The Public Governance of Collaborative Spaces: Discourse, Design and Democracy,” Public Administration, Vol. 83, No. 3, 2005, pp. 573-596. doi:10.1111/j.0033-3298.2005.00463.x

[12] E.-H. Klijn, "Governance and Governance Networks in Europe,” Public Management Review, Vol. 10, No. 4, 2008, pp. 505-525. doi:10.1080/14719030802263954

[13] M. Fenger and V. Bekkers, "The Governance Concept in Public Administration,” In V. Bekkers, G. Dijkstra, A. Edwards and M. Fenger, Eds., Governance and the Democratic Deficit, Assessing the Democratic Legitimacy of Governance Practises, Ashgate, Aldershot, England, 2007.

[14] R. A. W. Rhodes, "Governance and Public Administration,” In J. Pierre, Ed., Debating Governance, Authority, Steering and Democracy, Oxford University Press, Oxford, UK, 2000, pp. 54-90.

[15] W. J. Kickert, E.-H. Klijn and J. F. M. Koppenjan, Eds., "Managing Complex Networks: Strategies for the Public Sector,” Sage, London, 1997.

[16] J. Hartley, "Innovation in Governance and Public Services: Past and Present,” Public Money \& Management, 2005, pp. 27-34.

[17] S. Adam and H. Kriesi, "The Network Approach,” In P. A. Sabatier, Ed., Theories of the policy process, Westview Press, Cambridge, MA, 2007, pp. 129-154.

[18] J. W. Meek, J. De Ladurantey and W. H. Newell, "Complex Systems, Governance and Policy Administration Consequences," Emergence: Complexity and Organization, Vol. 9, No. 1/2, 2007, pp. 24-36.

[19] G. Teisman, A. Van Buuren and L. Gerrits, "Managing Complex Governance Systems," Routledge, London, 2009.

[20] C. De Boer and H. Bressers, "Contextual Interaction Theory as a Conceptual Lens on Complex and Dynamic Implementation Process," A Paper Presented at Research Conference COMPACT Work: Challenges of Making Public Administration and Complexity Theory Work, Rotterdam, The Netherlands, 2011.

[21] M. Maula, “Organizations as Learning Systems, Living Composition as an Enabling Infrastructure, Advanced Series in Management,” Elsevier, Amsterdam, 2006.

[22] A. A. Altshuler and M. D. Zegans, "Innovation and Public Management: Notes from the State House and City Hall,” In A. A. Altshuler and R. D. Behn, Eds., Innovation in American Government. Challenges, Opportunities, and Dilemmas, Brookings Institution Press, Washington
D.C., 1997, pp. 68-80.

[23] P. F. Drucker, "Innovation and Entrepreneurship: Practices and Principles,” Butterworth-Heinemann Ltd, Oxford, 1985.

[24] J. Bessant, High-Involvement Innovation, Building and Sustaining Competitive Advantage Through Continuous Change,” John Wiley \& Sons, West Sussex, 2003.

[25] S. Osborne and K. Brown, "Managing Change and Innovation in Public Service Organizations,” Routledge, London and NY, 2005.

[26] E. Mitleton-Kelly, "Ten Principles of Complexity and Enabling Infrastructures,” In E. Mitleton-Kelly, Ed., Complex Systems and Evolutionary Perspectives on Organizations: The Application of Complexity Theory to Organizations, Pergamon, 2003, pp. 23-50.

[27] M. Mitchell, “Complexity: A guided tour,” Oxford University Press, Oxford, UK, 2009.

[28] G. Morcöl, "Issues in Reconceptualising Public Policy from the Perspective of Complexity Theory,” Emergence: Complexity and Organization, Vol. 12, No. 1, 2010, pp. 52-60.

[29] E. Eppel, “The Application of a Complexity Analytical Lens to Understanding and Explaining Public Policy Processes," A paper presented at Research Conference COMPACT Work: Challenges of Making Public Administration and Complexity Theory Work, Rotterdam, The Netherlands, 2011.

[30] H. Raisio, "Embracing the Wickedness of Health Care-Essays on Reforms, Wicked Problems and Public Deliberation," Acta Wasaensia No 228, Social and Health Management 5, Universitatis Wasaensis, 2010.

[31] E. W. Johnston, K. Desouza and Q. Hu, "How the Application of Complexity and Policy Informatics to Public Administration Can Change the Questions We Ask and the Solutions We Discover," A paper presented at Research Conference COMPACT Work: Challenges of Making Public Administration and Complexity Theory Work, Rotterdam, The Netherlands, 2011.

[32] D. Marshall and G. B. Rossman, "Designing Qualitative Research,” Sage Publications, Thousand Oaks, 2006.

[33] M. Castells and P. Himanen, "The Information Society and the Welfare State-The Finnish Model, Oxford University Press, Oxford, UK, 2002.

[34] R. K. Yin, "Case Study Research, Design and Methods, 3rd Edition, Sage, Thousand Oaks, CA, 2003.

[35] B. Flyvbjerg, "Five Misunderstandings About Case-Study Research,” Qualitative Inquiry, Vol. 12, No. 2, 2006, pp. 219-245. doi:10.1177/1077800405284363

[36] K. M. Eisenhardt, "Building Theories from Case Study Research,” Academy of Management, Vol. 14, No. 4, 1989, pp. 532-550. doi:10.2307/258557

[37] S. Borins, "Public Management Innovation: Toward a Global Perspective," American Review of Public Administration, Vol. 31, No. 1, 2001, pp. 5-51. doi:10.1177/02750740122064802

[38] E. M. Rogers, "Diffusion of innovations," $5^{\text {th }}$ Edition, 
Free Press, New York, NY, 2003.

[39] M. B. Sanger and M. A. Levin, "Using Old Stuff in New Ways: Innovation as a Case of Evolutionary Tinkering," Journal of Policy Analysis and Management, Vol. 11, No. 1, 1992, pp. 88-15.

[40] J. Newman, J. Raine and J. Skelcher, “Transforming Local Government: Innovation and Modernization,” Public Money \& Management, 2001, pp. 61-68. doi:10.1111/1467-9302.00262

[41] M. Dodgson, D. Grann and A. Salter, "Think, Play, Do,” Oxford University Press, Oxford, 2005.

[42] P. Ormerod, "Why Most Things Fail: Evolution, Extinction and Economics," Faber and Faber, London, 2005.

[43] G. Bhatta, "Don't Just do Something, Stand There! - Revisiting the Issue of Risks in Innovation in the Public Sector,” The Innovation Journal, Vol. 8, No. 2, 2003.

[44] R. Walker, "Innovation Type and Diffusion: An Empirical Analysis of Local Government," Public Administration, Vol. 84, 2006, pp. 311-335. doi:10.1111/j.1467-9299.2006.00004.X

[45] C. Hood, “A Public Management for All Seasons?” Public Administration, Vol. 69, No. 1, 1991, pp. 3-9. doi:10.1111/j.1467-9299.1991.tb00779.x

[46] J. Fonseca, "Complexity and innovation in organizations,” Routledege, New York, NY, 2002.

[47] T. M. B. Aasen, "Innovation as Social Processes: A Participative Study of the Statoil R \& D Program Subsea Increased Oil Recovery (SIOR)," Norwegian University of Science and Technology, 2009.

[48] H. A. Simon, "Rationality as Process and a Product of Thought”, American Economic Review, Vol. 68, 1978, pp. 1-14.

[49] J. Bessant, "Dealing with Discontinuous Innovation: The European Experience," International Journal of Technology Management, Vol. 42, No. 1/2, 2008, pp. 36-50. doi:10.1504/IJTM.2008.018059

[50] W. E. Souder and K. D. Moenaert, "Integrating Marketing and R\&D Project Personnel within Innovation Projects: An Information Uncertainty Model,” Journal of Management Studies, Vol. 29, No. 4, 1992, pp. 485-512. doi:10.1111/j.1467-6486.1992.tb00675.x

[51] S. Cantarello, A. Nosella, G. Petroni and K. Venturini, "External Technology Sourcing: Evidence from DesignDriven Innovation,” Management Decision, Vol. 49, No. 6, 2011. doi:10.1108/00251741111143630

[52] R. J. Macdonald and W. Jinliang, “Time, Timeliness of Innovation, and the Emergence of Industries," Technovation, Vol. 14, No. 1, 1994, pp. 37-53. doi:10.1016/0166-4972(94)90069-8

[53] J. R. B. Halbesleben, M. M. Novicevic, M. G. Harvey and M. R. Buckley, "Awareness of Temporal Complexity in Leadership of Creativity and Innovation: A Competency-Based Model,” Leadership Quarterly, Vol. 14, No. 4, 2003, pp. 433-454. doi:10.1016/S1048-9843(03)00046-8

[54] M. Moensted, "High-Tech, Uncertainty, and Innovation,
The Opportunity for High-Tech Entrepreneurship,” In M. Bernasconi, S. Harris and M. Moensted, Eds., High-Tech Entrepreneurship-Managing innovation, variety and uncertainty, Routledge, London, 2006, pp. 15-32.

[55] J. Stiglitz, "Information and the Change in the Paradigm in Economics,” The American Economic Review, Vol. 92, No. 3, 2002, pp. 460-501. doi:10.1257/00028280260136363

[56] R. L. Daft and R. H. Lengel, "Organizational Information Requirements, Media Richness and Structural Design," Management Science, Vol. 32, No. 5, 1986, pp. 554-571. doi:10.1287/mnsc.32.5.554

[57] D. E. Brashers, "Communication and Uncertainty Management,” Journal of Communication, 2001, pp. 477-497. doi:10.1111/j.1460-2466.2001.tb02892.x

[58] J. D. Johnson, "Information Seeking-An organizational dilemma,” Quorum Books, London, 1996.

[59] D. Johnson, "What is Innovation and Entrepreneurship? Lessons for Larger Organizations," Industrial and Commercial Training, Vol. 33, No. 4/5, 2001, pp. 135-140. doi:10.1108/00197850110395245

[60] D. Gerwin and J. C. Tarondeau, "Case Studies of Computer Integrated Manufacturing Systems: A View of Uncertainty and Innovation Processes," Journal of Operations Management, Vol. 2, No. 2, 1982, pp. 87-99. doi:10.1016/0272-6963(82)90025-0

[61] A. C. R. Van Riel, J. Lemmink and H. Ouwersloot, "High-Technology Service Innovation Success: A Decision-Making Perspective," The Journal of Product Innovation Management, Vol. 21, 2004, pp. 348-359. doi:10.1111/j.0737-6782.2004.00087.x

[62] R. S. Hanft and S. P. Korper, "Some Notes on Uncertainty, Federal Policy and Innovation," Computers in Biology and Medicine, Vol. 11, 1981, pp. 1-7. doi:10.1016/0010-4825(81)90010-X

[63] J. Foster, "Productivity, Creative Destruction and Innovation Policy: Some Implications from the Australian Experience,” Innovation: Management, policy \& practice, Vol. 12, 2010, pp. 355-368.

[64] A. M. Pettigrew and S. Massini, "Innovative forms of Organizing: Trends in Europe, Japan and the USA in the 1990s,” In A. M. Pettigrew, R. Whittington, L. Melin, C. Sánchez-Runde, F. Van Den Bosch, W. Ruigrok and T. Numagami, Eds., Innovative forms of Organizing, International perspectives, Sage Publications, London, 2003, pp. 1-32.

[65] F. Johansson, "The Medici Effect-Breakthrough Insights at the Intersection of Ideas, Concepts, and Cultures,” Harvard Business School Press, Boston, 2004.

[66] A. Lam, “Organizational Innovation,” In: J. Fagerberg, D. C. Mowery and R. R. Nelson, Eds., The Oxford Handbook of innovation, New York, NY: Oxford University Press, 2005, pp. 115-147.

[67] H. Chesbrough, W. Vanhaverbeke and J. West, "Open Innovation: Researching a New Paradigm,” Oxford University Press, Oxford, UK, 2006. 
[68] L. Gaster, “Quality in Public Services,” Open University Press, Buckingham, 1995.

[69] G. Morcöl, "Why Complexity Theory? What Kind of a Theory is it?" A paper presented at Research Conference COMPACT Work: Challenges of Making Public Administration and Complexity Theory Work, Rotterdam, The Netherlands, 2011.

[70] R. Stacey, "Complexity and Organizational Realities: Uncertainty and the Need to Rethink Management after the Collapse of Investment Capitalism,” Routledge, London, 2010.

[71] J. Kooiman, "Governance and Governability: Using Complexity, Dynamics and Diversity," In J. Kooiman, Ed., Modern governance, New Government-Society Interactions, Sage Publications, London, 1993, pp. 35-48.

[72] N. Luhmann, "Social systems,” Stanford University Press, Stanford, CA, 1995.

[73] D. Byrne, "Complexity Theory and the Social Sciences, Routledge, London, 1998.

[74] P. Cilliers, "Complexity and Postmodernism," Routledge, London, 1998.

[75] R. Stacey and D. Griffin, "Complexity and the Experience of Managing in Public Sector Organizations," Routledge, London, 2005.

[76] H. Jalonen and P. Juntunen, "Managing Innovations in Complex Welfare Systems," Proceedings of the 6th International Conference on E-Government, Cape University of Technology, Cape Town, South Africa, 2010.

[77] D. J. Snowden and M. E. Boone, “A Leader’s Framework for Decision Making,” Harvard Business Review, 2007, pp. 1-9.

[78] C. Pollitt, "Complexity Theory and Evolutionary Public Administration: A Skeptical Afterword,” In G. R. Teisman, A. Van Buuren and L. Gerrits, Eds., Managing Complex Governance Systems: Dynamics, Self-Organization and Coevolution in Public Investments, Routledge, London, 2009, pp. 213-230.

[79] J. A. Goldstein, "Emergence as a Construct: History and Issues,” Emergence, Vol. 1, No. 1, 1999, pp. 49-72. doi:10.1207/s15327000em0101_4

[80] J. K. Hazy, J. A. Goldstein and B. B. Lichtenstein, “Complex Systems Leadership Theory New Perspectives from Complexity Science on Social and Organizational Effectiveness,” ISCE Publishing, Mansfield, 2007.

[81] H. Laihonen and A. Lönnqvist, "Grasping the Intangibility of Service Operations,” International Journal of Knowledge-Based Development, Vol. 1, No. 4, 2010, pp. 331345. doi:10.1504/IJKBD.2010.038042

[82] S. A. Kauffman, "At Home in the Universe: The Search for the Laws of Self-Organization and Complexity," Oxford University Press, Oxford, UK, 1995.

[83] H. Rittel and M. Webber, "Dilemmas in a General Theory of Planning,” Policy Sciences, Vol. 4, No. 2, 1973, pp. 155-169. doi:10.1007/BF01405730

[84] K. Kernaghan, "Integrating Values into Public Service: The Values Statements as Centerpiece,” Public Admini- stration Review, Vol. 63, No. 3, 2003, pp. 711-719. doi:10.1111/1540-6210.00334

[85] K. N. Kalu, "Entrepreneurs or Conservatives? Contractarian Principles of Bureaucratic Performance,” Administration and Society, Vol. 35, No. 5, 2003, pp. 539-563. doi:10.1177/0095399703256161

[86] D. A. Schön, "Beyond the Stable State: Public and Private Learning in a Changing Society,” Penguin, Harmondsworth, 1973.

[87] K. McLaughlin, S. Osborne and E. Ferlie, “The New Public Management: Current Trends and Future Prospects,” Routledge, London, 2002.

[88] J. Jalava, "Trust as a Decision, The Problems and Functions of Trust in Luhmannian Systems Theory," Doctoral Dissertation, Research Reports, University of Helsinki, Helsinki, 2006.

[89] D. Hjorth, "Creating Space for Play/Invention-Concepts of Space and Organizational Entrepreneurship," Entrepreneurship and Regional Development, Vol. 16, No. 5, 2004, pp. 413-432. doi:10.1080/0898562042000197144

[90] N. Luhmann, “Trust and Power,” Jonhn Wiley and Sons, New York, 1979.

[91] K. R. Popper, "The Myth of the Framework: In Defence of Science and Rationality,” Routledge, New York, 1996.

[92] L. Lambert, "Towards a Theory of Constructivist Leadership,” In L. Lambert, D. Walker, D. P. Zimmerman, J. E. Cooper, M. D. Lambert, M. E. Gardner and P. J. F. Slack, Eds., The Constructivist Leader, Teachers College Press, New York, 1995, pp. 28-51.

[93] C. Lechner and M. Dowling, "Firm Networks: External Relationships as Sources for the Growth and Competitiveness of Entrepreneurial Firms,” Entrepreneurship \& Regional Development, Vol. 15, No. 1, 2003, pp. 1-26. doi:10.1080/08985620210159220

[94] J. G. March, "Organizational Information Requirements, Media Richness and Structural Change," Management Science, Vol. 32, No. 5, 1994, pp. 554-571.

[95] L. Gales and D. Mansour-Cole, "User Involvement in Innovation Projects: Toward an Information Processing Model,” Journal of Engineering Technology Management, Vol. 12, 1995, pp. 77-109. doi:10.1016/0923-4748(95)00005-7

[96] E. Von Hippel, "Sticky Information and the Locus of Problem Solving: Implications for Innovation,” Management Science, Vol. 40, No. 4, 1994, pp. 429-439. doi:10.1287/mnsc.40.4.429

[97] M. Granovetter, “The Strength of Weak Ties,” American Journal of Sociology, Vol. 78, No. 6, 1973, pp. 13601380. doi:10.1086/225469

[98] G. Ahuja, “Collaboration Networks, Structural Holes, and Innovation: A Longitudinal Study,” Administrative Science Quarterly, Vol. 45, No. 3, 2000, pp. 425-455. doi: $10.2307 / 2667105$

[99] M. T. Hansen, “The Search-Transfer Problem: The Role of Weak Ties in Sharing Knowledge Across Organization Subunits,” Administrative Science Quarterly, Vol. 44, No. 
1, 1999, pp. 82-102. doi:10.2307/2667032

[100] W. Lidwell, K. Holden and J. Butler, "Universal Principles of Design,” Rockport, Gloucester, Mass, 2003.

[101] J. H. III. Clippinger, "The Biology of Business: Decoding the Natural Laws of Enterprise,” Jossey-Bass Publishers, San Francisco, 1999, pp. 1-30.

[102] A. Burwick and G. Kirby, "Using Vouchers to Deliver Social Services: Learning from the Goals, Uses, and Key Elements of Existing Federal Voucher Programs," Department of Health and Human Services, Office of the Assistant Secretary for Planning and Evaluation, United States, 2007.

[103] R. Katz and T. J. Allen, "Investigating the Not Invented Here (NIH) Syndrome: A Look at the Performance, Tenure and Communication Patterns of $50 \mathrm{R} \& \mathrm{D}$ Project Groups,” $R$ \& D Management, Vol. 12, 1982, pp. 7-19. doi:10.1111/j.1467-9310.1982.tb00478.x

[104] N. Levina and E. Vaast, "The Emergence of Boundary Spanning Competence in Practice: Implications for Implementation and Use of Information Systems," MIS Quarterly, Vol. 29, No. 2, 2005, pp. 335-363.

[105] P. Juntunen and J. Leinonen, "PARAS \& PEST-Exploring Affective Factors in the Planning Stage of Local Government Reform," Paper Presented at the European Group of Public Administration Conference, Malta, 2009.
[106] G. Stoker, "Governance as Theory: Five Propositions," International Social Science Journal, Vol. 50, No. 155, 1998, pp. 17-28. doi:10.1111/1468-2451.00106

[107] S. Goss, "Making Local Governance Work, Networks, Relationships and the Management of Change,” Palgrave, Great Britain, 2001.

[108] J. Kooiman, “Governing as Governance,” Sage Publications, London, 2003.

[109] J. Kooiman, "Modern Governance, New GovernmentSociety Interactions,” Sage Publications, London, 1990.

[110] J. A. Goldstein, "Emergence, Creativity, and the Logic of Following and Negating," The Innovation Journal: The Public Sector Innovation Journal, Vol. 10, No. 3, 2003.

[111] B. Flyvbjerg, "Making Social Science Matter: Why Social Inquiry Fails and How it Can Succeed Again," Cambridge University Press, Cambridge, 2001.

[112] P. Shaw, "Changing Conversations in Organizations: A Complexity Approach to Change,” Routledge, London, 2002. doi:10.4324/9780203402719

[113] T. Brown, M. Potoski and D. Van Slyke, "Simple and Complex Contracting,” PA Times, Vol. 7, No. 31, 2008.

[114] R. D. Stacey, "Strategic Management and Organisational Dynamics: The Challenge of Complexity to Ways of Thinking about Organisations,” 5th Edition, Prentice Hall, London, 2007. 